\title{
Isolation of Rhamnocitrin Insecticide from Retamaraetam via Shephadex LH-20
}

\author{
Marzough Aziz Dager Albalawi \\ Department of Chemistry University college- Alwajh, University of Tabuk, Saudi Arabia
}

\begin{abstract}
Retamaraetam is a medicinal herb growing wild in the mountain alkurvillage was collected in the flowering stage and after treatment in ways different methods of chromatography for isolated Rhamnocitrin has been purified bySephadex LH-20 and identified by spectroscopic methods (UV, NMR). showed that despite the differences in potency of Retamaraetamand Rhamnocitrinsubstances they were found to possess parallel regression lines. This may suggest that these extracts have the same mode of action against the tested insect larvae.
\end{abstract}

Keywords: Retamaraetam, Fabaceae, Alwajh, Rhamnocitrin,insecticide.

\section{Introduction}

Plants have formed the basis of sophisticated traditional medicine systems that have been used for thousands of years in countries, such as China [1] and India [2].The use of plants in the traditional medicine of many other cultures has been extensively documented. These plant based systems continue to play an important role in health care and it has been estimated by the World Health Organization that approximately $80 \%$ of the world's inhabitants rely mainly on traditional medicines for their primary health care, while plant products also play an important role in the health care systems of the remaining $20 \%$ of the population mainly residing in developed countries [3].

Retamaraetamis a spontaneous shrub legume belonging to the Fabaceae; it is one of the most important plants in the east Mediterranean deserts. In Tunisia this shrub legume plays an important ecological role, it is widely used in dune stabilisation and soil fixation. In addition, R. raetamis able to produce important quantities of biomass that are used as forage and for treating various human and animal diseases. Due to their capacity to enter into symbiosis with legume nodulating bacteria (LNB) collectively called rhizobia, R. raetamcould play an important role in the nitrogen cycle. They may be used to restore or increase fertility of degraded and eroded soils[4].

As the plant is being used extensively as an herbal medicine, it is necessary to have knowledge of the constituents of the plant .

In 2014, investigated $R$. raetam shoots antioxidant and antimicrobial activities and its natural antioxidant contents obtained from four fractions (petroleum ether, acetone $60 \%$, ethyl acetate and water). Results showed that the ethyl acetate fraction exhibits the highest antioxidant activity as compared to the other ones.). Moreover, RP-HPLC analysis showed that syringic acid and coumarin were the major phenolic compounds. Furthermore, this moderately polar fraction showed considerable antibacterial properties against human pathogen strains especially against Escherichia coli andBacillus cereus. Finally, fractionation allows the identification of $R$. raetam most active molecules and therefore the optimization of their utilization. Our findings pointed out the appropriate solvent for extracting $R$. raetam potent phenolics which might provide a rich and novel source of natural antioxidants as food additives replacing synthetic ones in food industry [5].

Two new flavones were isolated from the aerial parts of Retamaraetamsubsp. raetam. Their structures were established as luteolin 4'-O-neohesperidoside (1) and5,4'-dihydroxy-(3",4"-dihydro-3",4"-dihydroxy)$2^{\prime \prime}, 2^{\prime \prime}$-dimethylpyrano-( $\left.5^{\prime \prime}, 6^{\prime \prime}: 7,8\right)$-flavone (2) by means of spectroscopic methods. Also present was ephedroidin (4',5,7-trihydroxy-8-(2-hydroxy-3-butenyl)-flavone) [6].

\section{Materials And Methods}

For the study, Aerial parts of the herb was collected from Al-Khur Village in Al-Wajh Province at Tabuk area, North- Western, Saudi Arabia. It is grown widely on montains, during the rainy season (JAN, 2016). The original sample was classified and identified according to their family, genes and specie by Professor Amal Fakhry, Department of Botany, University of Tabuk.

Chemical reagents and instrumentation

NMR spectroscopy: ${ }^{1} \mathrm{H}$ and ${ }^{13} \mathrm{CNMR}$ spectroscopy was performed on a Bruker 300 NMR spectrometer using deuterated solvents as internal standards. 
Steady state UV-Vis absorption spectroscopy: Steady state absorption spectra were obtained using a spectrophotometer model UV - $240(200-600 \mathrm{~nm})$. All spectra were recorded using a quartz glass cuvette of 10x10 mm.

General remarks: Column chromatography was performed using Flash column Shephadex (LH-20) blocked Silica Gel (35-60 mesh). All chemicals were purchased from Sigma Aldrich and were of reagent grade.

\section{Extraction and isolation}

Dry herbs materials(4 Kg) were powdered and extracted by warm ethanol (80\%). The solvent was evaporated by rotary evaporator and the residue $(398 \mathrm{~g})$ was kept for further isolation chromatography methods and biological activities. The crude extract was chromatographed on a silica gel column $((6 \times 70 \mathrm{~cm})$ blocked Silica Gel (35-60 mesh) with (Benzene : Ethyl acetate, 9:1) to yield 100 fractions. The fraction number 93was purified using Flash column Shephadex (LH-20) with absolute ethanol to afford compound MR (17mg).

\section{Tested insects}

Preliminary toxicological bioassay tests were carried out to the selected plant extracts on tested insects according to a cited method after modification by Kamel, et al. 2005, Eldiasty, et al. 2014 and El-Ghaban, et al. 2015. Mosquitoes were maintained in a walk-insectaries under controlled conditions of temperature $\left(27 \pm 2{ }^{\circ} \mathrm{C}\right)$, relative humidity, R.H. (70\%-80\%) and light - dark period (16: $8 \mathrm{hrs}$.) under a fluorescent light. Larvae of the tested mosquito species were reared in white enamel pans $(35-40 \mathrm{~cm}$ diameter and $10 \mathrm{~cm}$ depth) containing about 1.5 L of de-chlorinated tap water. Larvae were provided with tetra-amine (tropical fish food) sprinkled twice daily over the water surface of the breeding pans. The water containing larvae was gently transferred every 2 days into clean enamel pans to avoid formation of scum on the water surface or on the walls and bottoms of pans. The breeding water was gently aerated for about 5 minutes every day by means of a small air pump.

Developed pupa were collected and transferred daily to plastic cups containing saline water then introduced into the breeding screened wooden cages $\left(30 \times 30 \times 30 \mathrm{~cm}^{3}\right)$. Emerged adults were fed on $10 \%$ sugar solution. After three days adults were fed on blood to lay egg batches were transferred to the white enamel pans containing de-chlorinated tap water for hatching. When mosquito larvae developed to the $2^{\text {nd }}$ instars, they were poured into clean pans and observed daily. Late third larval instars were used for toxicological studies as described previously for Culexpipiens [7].

Identification of compound MR:

\section{Results And Discussion}

Name: 7-O-Methyl Kaempferol (Rhamnocitrin)

Weight: $17 \mathrm{mg}$<smiles>COc1cc(O)c2c(=O)c(O)c(-c3ccc(O)cc3)oc2c1</smiles>

Molecular: $\mathrm{C}_{16} \mathrm{H}_{12} \mathrm{O}_{6}$

Molecular weight: 300

Shape: powder

Color: yellow

Melting point: $224^{\circ} \mathrm{C}$

Spectral Characteristics

The ultraviolet/visible light absorption spectrum of compound MR is presented in Figure 1.

Table 1: UV Spectrum data $\left(\lambda_{\max } \mathrm{nm}\right)$ of Compound MR

\begin{tabular}{|r|r|r|r|r|r|}
\hline $\mathrm{MeOH}$ & $+\mathrm{NaOMe}$ & $+\mathrm{AlCl}_{3}$ & $+\mathrm{AlCl} / \mathrm{HCl}$ & $+\mathrm{NaOAc}$ & $+\mathrm{NaOAc}_{3} \mathrm{H}_{3} \mathrm{BO}_{3}$ \\
\hline 270,363 & 278,399 & $274,305 \mathrm{sh}$, & $274,305 \mathrm{sh}$, & 276,364 & 276,364 \\
& & 348,424 & 348,424 & & \\
\hline
\end{tabular}



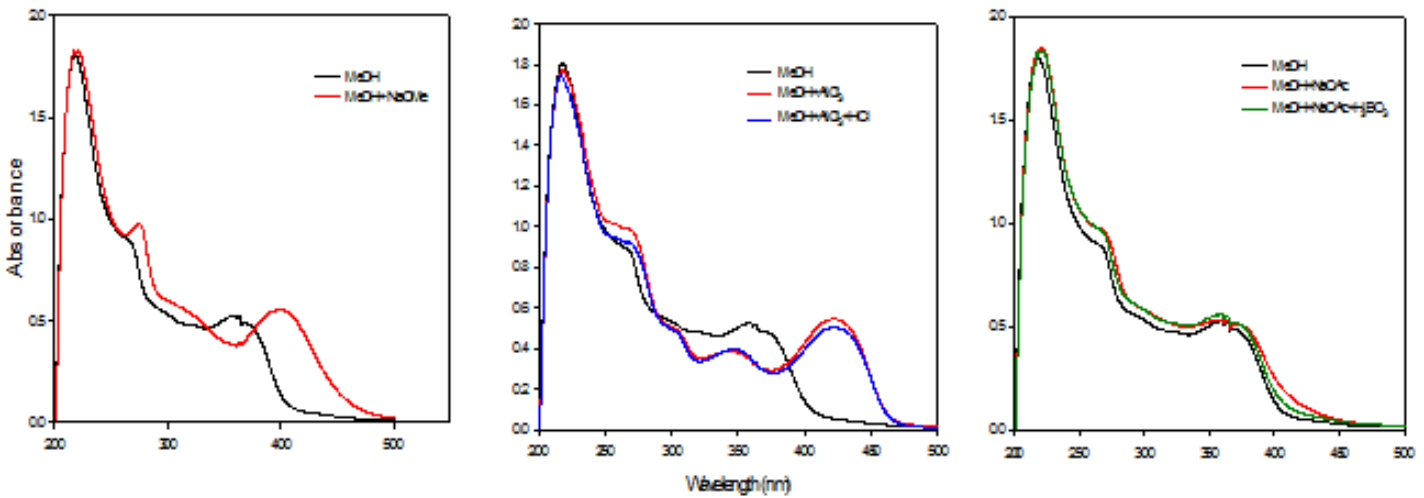

Ultraviolet/visible light absorption spectrum of CompoundMR

Fig.1.

Compound MRwas identified by using 1H-NMR, 13C-NMR. All spectroscopic data were resumed in table (3).

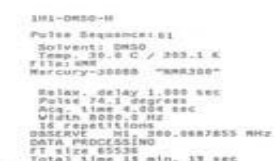

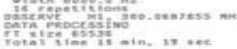

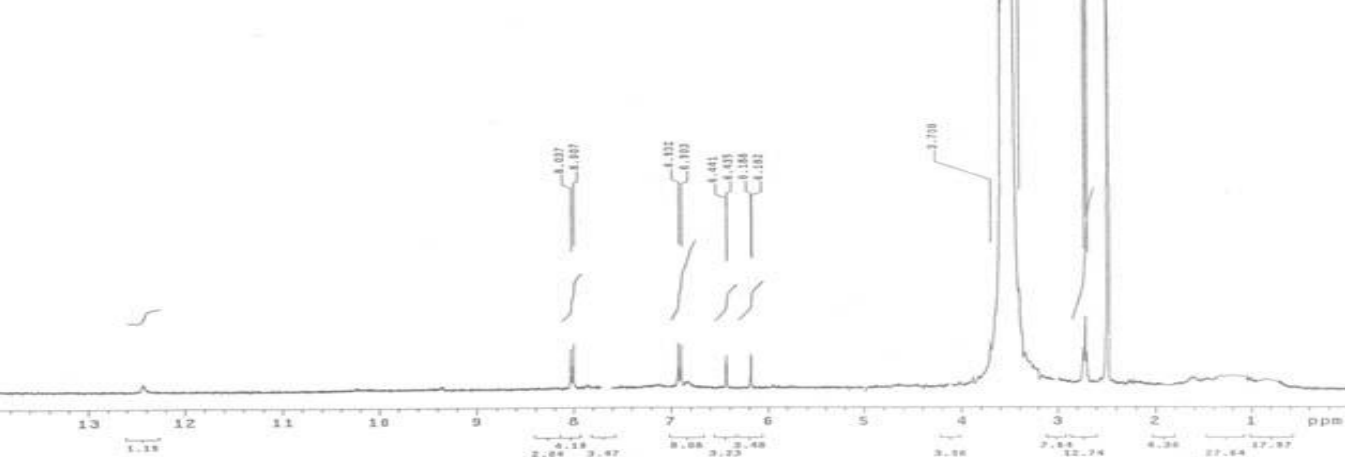

Fig. 2: ${ }^{1} \mathrm{H}$ NMR Spectrum of Compound MR
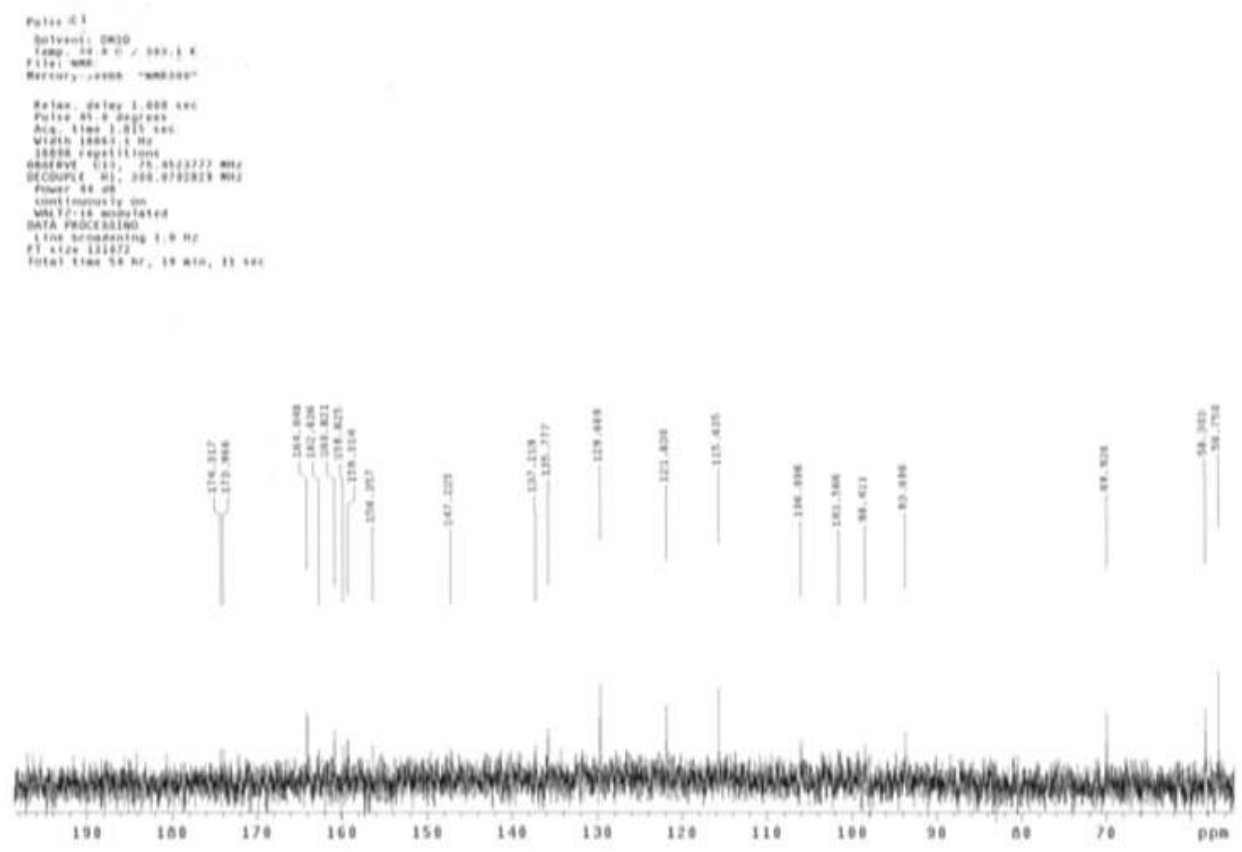

Fig.3: ${ }^{13} \mathrm{C}$ NMR Spectrum of Compound MR 
Table 2: ${ }^{1} \mathrm{H},{ }^{13} \mathrm{C}$ NMR Chemical Shifts of MR compound

\begin{tabular}{|c|c|c|c|}
\hline No. of $H$ & Chemical shift & No. of C & Chemical shift \\
\hline H-6 & $\begin{array}{l}\mathrm{d} 6.19 \\
(\mathrm{~J}=2.1 \mathrm{~Hz})\end{array}$ & C-2 & 147.2 \\
\hline H-8 & $\begin{array}{l}\mathrm{d} 6.44 \\
(\mathrm{~J}=2.4 \mathrm{~Hz})\end{array}$ & $\mathrm{C}-3$ & 135.8 \\
\hline H-2' & $\begin{array}{l}\mathrm{d} 8,03 \\
(\mathrm{~J}=8.7 \mathrm{~Hz})\end{array}$ & C-4 & 176.0 \\
\hline H-3' & $\begin{array}{l}\mathrm{d} 6.92 \\
(\mathrm{~J}=8.7 \mathrm{~Hz})\end{array}$ & C-5 & 160.8 \\
\hline H-5' & $\begin{array}{l}\mathrm{d} 6.92 \\
(\mathrm{~J}=8.7 \mathrm{~Hz})\end{array}$ & C-6 & 98.4 \\
\hline H-6' & $\begin{array}{l}\mathrm{d} 8,03 \\
(\mathrm{~J}=8.7 \mathrm{~Hz})\end{array}$ & C-7 & 164.0 \\
\hline $\mathrm{OCH}_{3}-7$ & s 3.46 & C-8 & 93.7 \\
\hline \multirow[t]{9}{*}{ OH-5 } & s 12.45 & C-9 & 156.4 \\
\hline & & C-10 & 106.0 \\
\hline & & C-1' & 121.8 \\
\hline & & C-2' & 129.7 \\
\hline & - & C-3' & 115.6 \\
\hline & & C-4' & 159.3 \\
\hline & & C-5' & 115.6 \\
\hline & & C-6' & 129.7 \\
\hline & & $\mathrm{OCH}_{3}-7$ & 56.7 \\
\hline
\end{tabular}

\subsection{Evaluation of the larvicidal activity of Ethanol Extracts(Retamaraetam \& Rhamnocitrin) on mosquito} larvae:

These experiments were carried out to evaluate the potency of Retamaraetam and Rhamnocitrinwhich extracted both by ethyl alcohol. The results from table (3) and fig. (4) showed that the Retamaraetamextract more potent than the Rhamnocitrinextract according to LC50 and LC95 values. The confidential limits of each of the tested extract were statistically calculated for LC50 and LC95 at P=0.05. The LC50 values were 138.28 and $206.77 \mathrm{ppm}$ for crude extract and the fraction respectively. The difference in potency between Retamaraetamextract and the Rhamnocitrinmay be attributed to the synergistic effect between the components of crude extract. Several authors have used the plant extracts to synergize each other and the insecticidal activities of the traditional insecticides[8-11]. The present data showed that despite the differences in potency of crude and fraction substances they were found to possess parallel regression lines. This may suggest that these extractshave the same mode of action against the tested insect larvae. The slope function reflects the homogeneity reaction of tested insects toward the tested substance. The lowering of slope function that meaning the more homogeneity of tested population [12-13].

Table 3: larvicidal activity of Ethanol Extracts(Retamaraetam\&Rhamnocitrin)on Culexpipiens larvae.

\begin{tabular}{|c|c|c|c|c|c|}
\hline Ethanol Extracts & Conc. ppm & Mortality \% & $\begin{array}{l}\text { LC 50 } \\
\text { (Co. Limits) }\end{array}$ & $\begin{array}{l}\text { LC 95 } \\
\text { (Co. Limits) }\end{array}$ & $\begin{array}{l}\text { Slope } \\
\text { Function }\end{array}$ \\
\hline \multirow{4}{*}{$\begin{array}{l}\text { Retamaraetam } \\
\text { (crude) }\end{array}$} & 50 & 1.28 & \multirow{4}{*}{$\begin{array}{l}138.28 \\
(126.72-150.91)\end{array}$} & \multirow{4}{*}{$\begin{array}{l}292.49 \\
(237.59 \\
360.24)\end{array}$} & \multirow[t]{4}{*}{5.1} \\
\hline & 100 & 23.82 & & & \\
\hline & 150 & 57.1 & & & \\
\hline & 200 & 97.12 & & & \\
\hline \multirow{5}{*}{$\begin{array}{l}\text { Rhamnocitrin } \\
\text { (fraction) }\end{array}$} & 100 & 1.7 & \multirow{5}{*}{$\begin{array}{l}206.77 \\
(195.40-218.81)\end{array}$} & \multirow{5}{*}{$\begin{array}{l}352.80 \\
(313.01 \\
397.70)\end{array}$} & \multirow[t]{5}{*}{7.1} \\
\hline & 150 & 18.3 & & & \\
\hline & 200 & 40.98 & & & \\
\hline & 250 & 67.21 & & & \\
\hline & 300 & 91.67 & & & \\
\hline
\end{tabular}

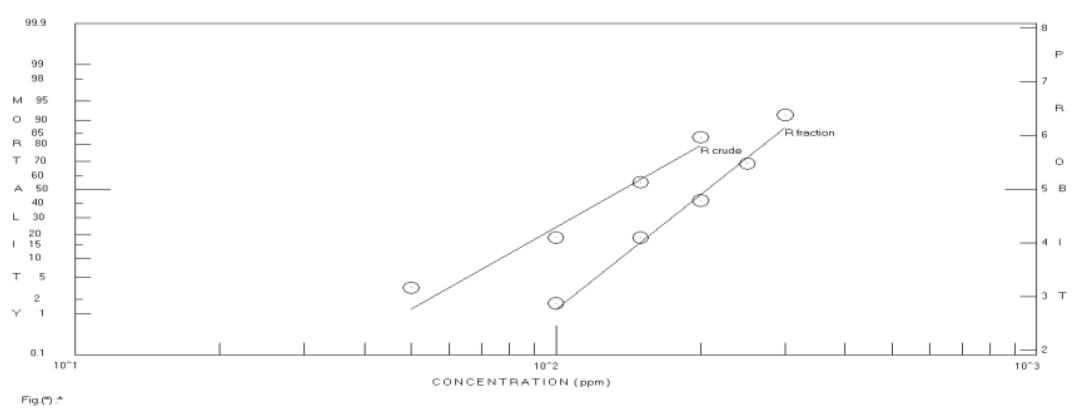

Fig. 4: Susceptibility of Culexpipienslarvae to Ethanol Extracts(Retamaraetam\&Rhamnocitrin) 


\section{Conclusion}

In conclusion, a combination of spectroscopic methods, chromatography, and biological testing was particularly useful for the rapid characterization of unknown active compounds of an extract. It is a great help in isolation and structure determination. Experimentssuggest that substances have the same mode of action against the tested insect larvae.

\section{References}

[1] Chang, H. M. and But, P. H. 1986. Pharmacology and Applications of Chinese Materia Medica, Vols 1 and 2, 1320. Singapore: World Scientific Publishing

[2] Farnsworth, N. R., Akerele, O., Bingel, A. S., Soejarto, D. D. and Guo, Z. 1985. Medicinal plants in therapy. Bulletin of the World Health Organization 63:965-981.

[3] Kapoor, L. D. 1990. CRC Handbook of Ayurvedic Medicinal Plants. Boca Raton, Florida: CRC Press. 416.

[4] MosbahMahdhi a, Ange 'leNzoue' b, Philippe de Lajudie b, Mohamed Mars a,*, Progress in Natural Science 18 (2008) $43-49$.

[5] SaadaMariem, FallehHanen, JalleliInès, SnoussiMejdi, KsouriRiadh, Phenolic profile, biological activities and fraction analysis of the medicinal halophyte Retama raetam, South African Journal of Botany, Volume 94, September2014, Pages 114-121.

[6] M. Kassem, S.A. Mosharrafa, N.A.M. Saleh, S.M. Abdel-Wahab, Two new flavonoids from Retamaraetam , Fitoterapia, Volume 71, Issue 6, December 2000, Pages 649-654.

[7] Abbassy, M.A., Abdelgaleil, S.A.M. and Rabie, R.Y.A. 2009. Insecticidal and synergistic effects of Majoranahortensis essential oil and some of its major constituents. J EntomoExperi et Applic. 131(3): 225 - 232.

[8] Busvine, J.R. 1971. A critical review of the techniques for testing insecticides. The Commonwealth Intit. Entomol., London: 345 p.

[9] EL-Bokl, M.M. and Moawad, H.M. 1997. Toxicity and joint action of some plant extracts against Cx. pipiens larvae. J. Union Arab Boil. 7 (A- Zoology): 449-461.

[10] Eldiasty, J.G., Hassan, M.M. and Kamel, O.M.H.M. 2014. Evaluation of some agricultural waste extracts against mosquito larvae, and some types of microorganisms as insecticidal and antibiotic agents. Egypt. Acad. J. Biolog. Sci., 6(1): 1-16.

[11] El-Ghaban, A.G.; Eldiasty, J.G. and Kamel, O.M.H.M. 2015. Evaluation of Rosmarinus species extracted by different solvents against mosquito larvae, Biomophalaria species and different pathogenic bacteria. J. adv. Sci. Res., 6 (4): 44 - 49.

[12] Kamel O M, Hassan M M, Abd El-Baky SMM, Hafez JA, Hamed MS, et al. J. Egypt. Acad. Soc. Environ. Develop. (A. Entomology). (2005 a); 6 (2): 277-289.

[13] Kamel OM, Hassan MM, Abd El-Baky SMM, Hafez JA, Hamed MS, et al. J. Egypt. Acad. Soc. Environ. Develop. (A. Entomology). (2005 b); 6 (2): 307-321.

[14] Kamel, O.M.H.M.; El-Ghaban, A.G. and Hassan, M.M. 2015. Evaluation of some medicinal plant extracts against mosquito Culexpipienslarvae and snail Biomphalariaalexandrina. Int. J. Rec. Adv. Multi. Rec., 2 (12): 1105 - 1109. 